\title{
Examination of wind storms over Central Europe with respect to circulation weather types and NAO phases
}

Article

Published Version

Donat, M. G., Leckebusch, G. C., Pinto, J. G. and Ulbrich, U. (2010) Examination of wind storms over Central Europe with respect to circulation weather types and NAO phases. International Journal of Climatology, 30 (9). pp. 1289-1300. ISSN 0899-8418 doi: https://doi.org/10.1002/joc.1982 Available at https://centaur.reading.ac.uk/32773/

It is advisable to refer to the publisher's version if you intend to cite from the work. See Guidance on citing.

Published version at: http://dx.doi.org/10.1002/joc.1982

To link to this article DOI: http://dx.doi.org/10.1002/joc.1982

Publisher: John Wiley \& Sons

All outputs in CentAUR are protected by Intellectual Property Rights law, including copyright law. Copyright and IPR is retained by the creators or other copyright holders. Terms and conditions for use of this material are defined in the End User Agreement.

www.reading.ac.uk/centaur 
Central Archive at the University of Reading

Reading's research outputs online 


\title{
Examination of wind storms over Central Europe with respect to circulation weather types and NAO phases
}

\author{
Markus G. Donat, ${ }^{a *}$ Gregor C. Leckebusch, ${ }^{\mathrm{a}}$ Joaquim G. Pinto ${ }^{\mathrm{b}}$ and Uwe Ulbrich ${ }^{\mathrm{a}}$ \\ ${ }^{a}$ Institute for Meteorology, Freie Universität Berlin, Germany \\ ${ }^{\mathrm{b}}$ Institute for Geophysics and Meteorology, University of Cologne, Germany
}

\begin{abstract}
The occurrence of wind storms in Central Europe is investigated with respect to large-scale atmospheric flow and local wind speeds in the investigation area. Two different methods of storm identification are applied for Central Europe as the target region: one based on characteristics of large-scale flow (circulation weather types, CWT) and the other on the occurrence of extreme wind speeds. The identified events are examined with respect to the NAO phases and CWTs under which they occur. Pressure patterns, wind speeds and cyclone tracks are investigated for storms assigned to different CWTs. Investigations are based on ERA40 reanalysis data.

It is shown that about $80 \%$ of the storm days in Central Europe are connected with westerly flow and that Central European storm events primarily occur during a moderately positive NAO phase, while strongly positive NAO phases (6.4\% of all days) account for more than $20 \%$ of the storms. A storm occurs over Central Europe during about $10 \%$ of the days with a strong positive NAO index. The most frequent pathway of cyclone systems associated with storms over Central Europe leads from the North Atlantic over the British Isles, North Sea and southern Scandinavia into the Baltic Sea. The mean intensity of the systems typically reaches its maximum near the British Isles. Differences between the characteristics for storms identified from the CWT identification procedure (gale days, based on MSLP fields) and those from extreme winds at Central European grid points are small, even though only $70 \%$ of the storm days agree. While most storms occur during westerly flow situations, specific characteristics of storms during the other CWTs are also considered. Copyright $($ ) 2009 Royal Meteorological Society
\end{abstract}

KEY WORDS wind storms; atmospheric circulation; circulation weather types; North Atlantic oscillation; extra-tropical cyclones; storminess

Received 7 January 2009; Revised 16 June 2009; Accepted 17 June 2009

\section{Introduction}

Intense winter storms constitute one of the most important natural hazards affecting Central Europe. For example, series of storms like those in January and February 1990 (e.g. Daria, Vivian), in December 1999 (e.g. Anatol, Lothar, cf. Ulbrich et al., 2001; Wernli et al., 2002) and more recently in January 2007 (e.g. Kyrill, cf. Fink et al., 2009) repeatedly raise public and scientific interest in these natural hazards. Whereas several recent works point to an increase in storminess in the recent decades until the late 1990s (e.g. Leckebusch et al., 2008a; Wang et al., 2009), other authors point out that the recent trend is just part of a decade-long variability and that there is no evidence that storminess over Europe in the early 1900s was different from that in recent decades (WASA group, 1998; Bärring and von Storch, 2004; Matulla et al., 2008). As extreme storms are rare events by definition, it is difficult to detect such changes from the events themselves. This

\footnotetext{
* Correspondence to: Markus G. Donat, Institut für Meteorologie, Freie Universität Berlin, Carl-Heinrich-Becker-Weg 6-10, 12165 Berlin, Germany. E-mail: markus.donat@met.fu-berlin.de
}

paper explores a path for future studies on changes in the large-scale conditions for storm occurrence by taking a closer look at the relation of storms and the large-scale patterns under which they occur.

The association of local weather with cyclones and large-scale flow patterns has been widely examined and applied in climatological studies. van Bebber (1891), for example, classified cyclone tracks with relevance for Europe, identifying the well-known Vb-track with a high potential for large summer floods in Europe. Within this context, weather typing approaches (Hess and Brezowsky, 1969; Lamb, 1972) are often used to classify large-scale weather situations and relate them to local variables; for instance, the circulation weather type (CWT) approach (see Jones et al., 1993) has been applied to different European regions, often in the context of investigating precipitation-relevant regimes (e.g. Goodess and Palutikof, 1998; Trigo and Dacamara, 2000). Motivated by this successful application, we consider it worthwhile to investigate large-scale atmospheric circulation associated with wind storm events, using a similar approach. For the British Isles and North Sea region, Jenkinson and Collison (1977) assigned the occurrence 
of gale days to different flow classes, finding a particular relevance of flow from the westerly sectors as well as southerly flow. For Central European storms, the westerly flow seems to be particularly important: Schmidtke and Scherrer (1997) suggested west wind storms as the most relevant destructive storm type (in terms of forest losses) affecting Switzerland in winter (besides southerly Foehn storms). Busch et al. (1998) mention westerly/northwesterly flow regimes as an important criterion for their classification of storm weather situations over the German Bight. Recently, Leckebusch et al. (2008b) showed that a small number of specific weather developments (i.e. temporal evolution of MSLP pattern over 3 days, $c f$. their Figure 3) are associated with over $70 \%$ of winter storms over Central Europe and especially Germany in recent decades. Hence, these and other studies document that the occurrence of storms over Europe occurred under 'preferred' large-scale conditions over the North Atlantic and Europe. A more detailed quantification of the relevance of specific large-scale flow patterns relevant for the occurrence of storm is, however, desirable.

With respect to the dominating variability pattern over the North Atlantic, the North Atlantic Oscillation (NAO, Walker, 1924; Hurrell, 1995), literature provides extended reviews on phenomenology, mechanisms and variability of the NAO, e.g. in Marshall et al. (2001) and Wanner et al. (2001). The link between the NAO phase and the occurrence of intense cyclones has been documented in previous studies (e.g. Serreze et al., 1997). Recently, Pinto et al. (2009) were able to show that an enhanced number of storms over the North Atlantic/European region during positive NAO phases (compared to negative NAO phases) is due to larger areas of suitable growth conditions. Raible (2007) found a NAO+-like pattern in the $500 \mathrm{hPa}$ geopotential height field being correlated with the occurrence of extreme cyclones over Northern Europe. With respect to the role of the NAO phase for the occurrence of wind storms, Matulla et al. (2008) mention that on a centennial time-scale the capability of the NAO index to explain storminess across Europe varies in space and with the period considered.

This study aims to achieve a better understanding of the relation between large-scale atmospheric circulation and the occurrence of severe winter storm events in Central Europe, including consideration of the associated extratropical cyclones. Atmospheric circulation is analysed in terms of the NAO phase and classified into CWTs with a focus on storm events. While the above-mentioned studies (e.g. Pinto et al., 2009) assign the occurrence of extreme North Atlantic cyclones to the NAO phase during the cyclones' development phase (irrespective of whether they hit Europe or not), a different approach is pursued here: For each wind storm event over Europe, the contemporaneous NAO phase and CWTs are considered in order to deduce their roles for storms in Central Europe. Storm days are identified using two different methods and examined in more detail for relevant circulation classes in order to provide an insight into their synoptic features.
For investigating storm-related atmospheric patterns, the main focus is laid on analysis of the related cyclone tracks and their intensities, on specific patterns of the mean sea level pressure (MSLP) and wind speed.

\section{Data and methods}

The investigations presented in this study are based on European Center Medium Range Weather Forecast reanalysis (Uppala et al., 2005, hereafter ERA40) for the 40-year period from 1961 to 2000. Mean sea level pressure (MSLP) data and daily maximum wind speeds are used. The latter were derived as the maximum of 4 instantaneous values from 00, 06, 12 and 18 UTC, as no integrated maximum value over all time steps is available from ERA40. This maximum of four instantaneous values is expected to be slightly lower than the maximum of all time steps (cf. Pinto et al., 2007a, their Figure 3(b) and (c)). As almost all severe damage-inducing storm events occur during the winter half year (Klawa and Ulbrich, 2003; Munich Re, 2007), analyses are restricted to the period from October to March. ERA40 reanalysis data have a spatial resolution of about $1.125^{\circ}$ (N80) and are also available interpolated on a $2.5^{\circ}$ grid. We performed the wind field analyses on the basis of the finer grid, whereas the CWT classification and cyclone tracking (both using MSLP data) were done on the coarser grid. This accounts for the characteristics and data requirements of both methods. We have not used the wind gust data from ERA40 as it has been regarded unreliable over areas of steep orography (Della-Marta et al., 2009). On the other hand, these authors see the 6-hourly instantaneous wind fields (the same data used here) as apparently being largely free from such problems, apart from somewhat too low speed over complex orography.

Large-scale atmospheric circulation is analysed from the characteristics of daily mean MSLP fields (calculated as the mean of four instantaneous output values per day). For the daily flow classification, an objective scheme is used that was initially described by Jenkinson and Collison (1977) and later published by Jones et al. (1993). This scheme is based on the original manual Lamb weather types (Lamb, 1972). Although this method does not consider the temporal evolution of weather situations and the flow analysis is specific for the central point of the investigation area, its objectivity and simplicity make it preferable for this specific application compared to, e.g. the subjective Grosswetterlagen classification (Hess and Brezowsky, 1969). The only required input parameter is the MSLP field. Originally developed for the region of the British Isles, it was also successfully applied to other European regions and has been widely used in the literature (see e.g. Buishand and Brandsma, 1997; Goodess and Palutikof, 1998; Trigo and Dacamara, 2000; Demuzere et al., 2008). Here, only the basic features are recapitulated. 
To classify flow characteristics, directional flow $(F)$ and vorticity $(Z)$ are calculated in geostrophical approximation based on the MSLP values of the surrounding $2.5 \times 2.5^{\circ}$ grid. On the basis of these terms, flow is classified into directional, (anti-) cyclonal or hybrid CWTs. The directional types are divided into eight sectors of $45^{\circ}$ : NE, E, SE, S, SW, W, NW and N. For each day, flow can thus be classified into 1 of 27 types ( 8 directional, 1 cyclonal (C), 1 anti-cyclonal (AC), 8 hybrid cyclonal-directional, 8 hybrid anti-cyclonal-directional and 1 undefined). Further details can be found in Jones et al. (1993). Here, largescale flow is classified for Central Europe (Figure 1(a)), focusing on $50^{\circ} \mathrm{N}, 10^{\circ} \mathrm{E}$. Hybrid weather types are considered each with half as occurrence of directional and half as (anti-) cyclonal flow in terms of frequency counts. Thus, the frequencies of overall 11 classes are determined (8 directional, 1 cyclonal, 1 anti-cyclonal, 1 undefined). The undefined class could also be omitted. The presented results are equivalent, if the days with undefined CWT ( $2.5 \%$ of all) were classified to the closest of the other CWTs (not shown).

In the classification scheme of circulation weather types (Jenkinson and Collison, 1977; Jones et al., 1993) also a gale index $G=\sqrt{\left(F^{2}+\left(\frac{1}{2} Z\right)^{2}\right)}$ is defined,

(a)

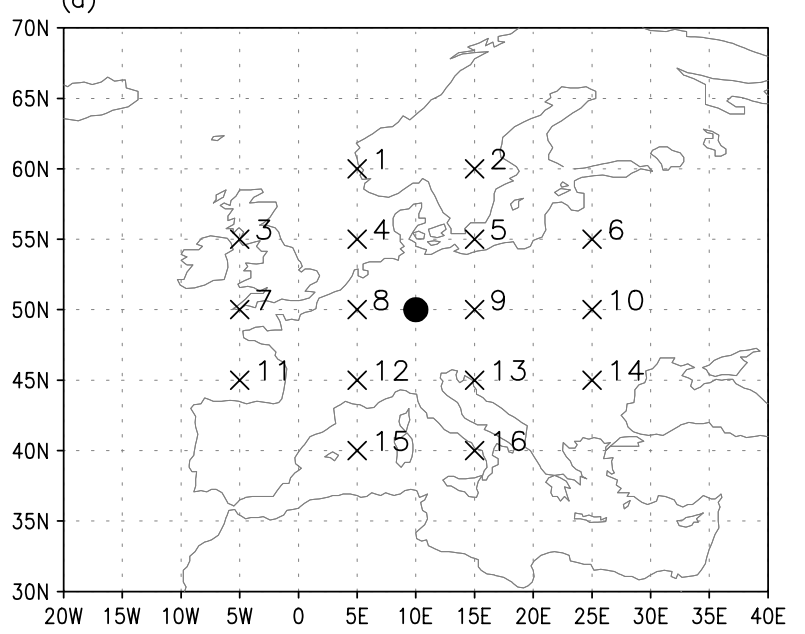

(b)

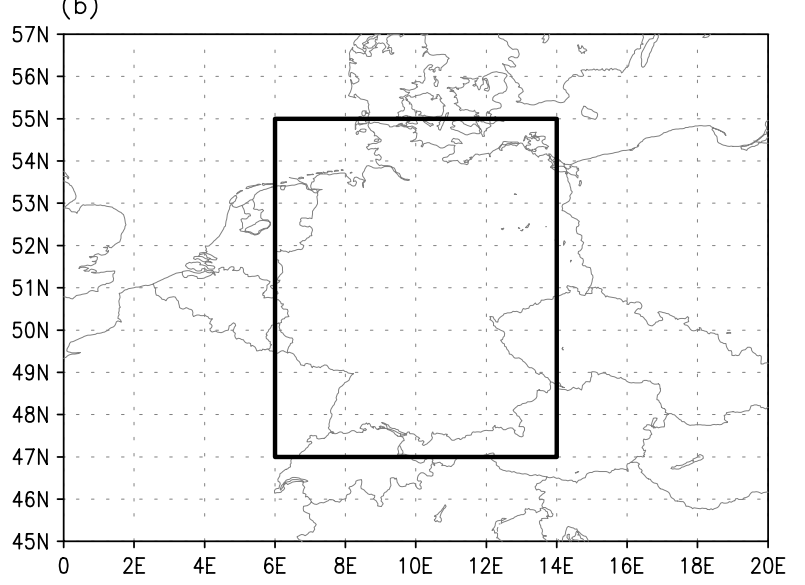

Figure 1. Investigation areas (a) for classification of CWTs and gale days, (b) for detection of storm days SP98. considering strength of directional flow $(F)$ and vorticity $(Z)$. Different thresholds for gale days $(G>30)$, severe gale days $(G>40)$ and very severe $(G>50)$ gale days are given for the region of the British Isles. For the Central European investigation area, about 15 gale days per winter season $(G>30)$ are detected in the ERA40 reanalysis data. By calibration towards a slightly higher threshold of $G>35$, the average number of detected gale days is 5.5 per winter ( 220 gale days in the ERA40 period 1961-2000). This is reasonable as it roughly reflects the number of extreme and destructive storm events (Munich Re, 1999, 2007) and corresponds to the number of severe gale days $(G>40)$ found for the British Isles and North Sea region. Although inevitably subjective, the chosen threshold is considered appropriate as the number of identified gale days corresponds well to storm frequencies considered in other studies (e.g. Klawa and Ulbrich, 2003; Della-Marta et al., 2009). Owing to the characteristics of our method, a single storm may be associated with several (consecutive) gale days, leading to a slightly higher number of storm days compared to storm events. These gale days based on the analysis of flow characteristics are hereafter denoted as JC35 $(G>35)$. This gale index was also used in other studies, e.g. by Hulme and Jones (1991) and Carnell et al. (1996).

The chosen criterion for gale days considers the characteristics of the daily mean MSLP field, hence estimating the geostrophic component of the large-scale winds (and does not implicitly take into account the incidence of strong winds). The striking and devastating phenomenon in the context of storms is, however, the occurrence of local extreme wind speeds. Therefore, an alternative criterion is applied to identify storm days related to local wind extremes at the ERA40 grid point in the area of interest. This allows a comparison with the storm days found from computation of the gale index $G$ based on large-scale geostrophic flow. The local 98th percentile of daily maximum wind speeds is deemed to be a common threshold for storm damage (e.g. Klawa and Ulbrich, 2003; Leckebusch et al., 2007; Pinto et al., 2007a). In a first step to identify storm days, all exceedances of the local 98th percentile of daily maximum wind speed during winter are registered for the region $6^{\circ} \mathrm{E}-14^{\circ} \mathrm{E}, 47^{\circ} \mathrm{N}-55^{\circ} \mathrm{N}$ (Figure 1(b)). This area roughly corresponds to the area of Germany. As severe windstorms are generally connected to wind fields covering large areas, the local 98th percentile (wind speed threshold) must be exceeded for a minimum number of ERA40 grid points (area threshold). In ERA40 (horizontal resolution $\sim 1.125^{\circ}$ ), the investigation area for storm detection consists of 49 grid boxes. If the area threshold is calibrated to a quarter of the grid boxes in the investigation area (i.e. 12), a reasonable number of days for consideration of severe storm events are identified as storm days in the ERA40 data. This threshold yields an average of 5.3 storm days per winter half year (214 in the 40-year period 1961-2000). This also corresponds well to the number of JC35 gale days. 
Identification and tracking of cyclones is performed by applying an objective algorithm developed by Murray and Simmonds (1991) and adapted to the Northern Hemisphere by Pinto et al. (2005). It is organized in two steps: First, cyclones are identified on the basis of the search for the maximum of the Laplacian $\left(\nabla^{2} p\right)$ of MSLP. Under quasi-geostrophic conditions, this is equivalent to the search for extremes of relative vorticity. Subsequently, a tracking algorithm is applied, taking into account the most probable displacement of the cyclone core under the given large-scale conditions and previous path and speed. As this methodology is to be applied to GCM data as well, we have chosen to perform the cyclone identification and tracking based on the ERA40 reanalysis data at the $2.5^{\circ}$ grid resolutions, in order to enable a later comparison between the ERA40 and GCM-based results (the sensitivity of cyclone statistics to spatial resolution of datasets was explored e.g. in Pinto et al., 2005).

For a more detailed investigation of the characteristics of storm events, the related cyclone track is assigned to each storm day by searching the most intensive cyclone passing a cyclone detection box (i.e. the area where cyclone tracks associated with the event can be expected, defined below) on that date. The intensity is measured in terms of the Laplacian of MSLP. Maximum winds usually occur south of a cyclone core in Central Europe. Thus, for the automatic assignment, only those cyclone tracks are considered that pass through the storm day detection area or north of it. The size of the cyclone detection box was calibrated to $0^{\circ} \mathrm{E}-20^{\circ} \mathrm{E}, 47^{\circ} \mathrm{N}-65^{\circ} \mathrm{N}$ (green box in Figure 5(c)). If two or more consecutive storm days can be related to the same cyclone track, this cyclone is only counted once for the composites of storm cyclones.

It was tested whether the automatic assignment of cyclones produces realistic results for major historical storm events during the years 1990 and 1999. For the storms Daria (Jan 25/26 1990), Herta (Feb 3/4 1990), Vivian (Feb 26/27 1990), Wiebke (Feb 27/28 1990), Anatol (Dec 3 1990) and Martin (Dec 28 1999), the related cyclone tracks were assigned successfully, i.e. in accordance with observations. However, in the case of Lothar (a fast-travelling secondary disturbance south of a strong steering cyclone, Dec 26 1999), the method does not produce the expected result. It assigns the deep steering cyclone to the wind storm, whereas the real track of Lothar is the one with the second highest intensity. This is due to the failure of the reanalysis to include Lothar's pressure anomaly realistically ( $c f$. Ulbrich $e t$ al., 2001). Thus, it must be assumed that the automatic procedure may assign stronger steering cyclones to a storm event instead of the secondary cyclone actually causing the storm.

During the whole considered ERA40 period 19612000 , only for 12 (of in total 220 , i.e. $\approx 5 \%$ ) gale days (JC35), no cyclone track can be assigned by this method. In most of these cases, there is a strong anti-cyclone over Northern Europe and easterly flow prevails (i.e., there is no cyclone inside the detection box to assign). A detailed consideration of these cases further showed that wind speeds are comparatively low, barely exceeding the gale index threshold (JC35) or the 98th percentile of wind speed (SP98).

The relation between gale days and contemporaneous NAO phases was also investigated. Therefore, a NAO index for the ERA40 dataset was calculated on a daily basis following Pinto et al. (2009). The NAO pattern is derived from monthly mean data (via principal component analysis of SLP) for the area $90^{\circ} \mathrm{W}-50^{\circ} \mathrm{E}$, $20^{\circ} \mathrm{N}-80^{\circ} \mathrm{N}$. As expected, the NAO is the leading principal component for this area (Pinto et al., 2009, their Figure 1). The 'daily NAO index' is obtained by projecting the monthly pattern onto the daily SLP data, followed by a 5 -day running mean smoothing. This approach for achieving a daily NAO index is similar to the method used by Blessing et al. (2005). To assign storms to NAO phases, the daily NAO index is then classified on the basis of the definitions given in Table I ('neutral', 'positive', 'negative', 'strong positive', 'strong negative'). These NAO classes are the same as those used by Pinto et al. (2009). Next, the NAO-index value on the date of storm occurrence (gale day) over central Europe is considered for further analysis. This is a slight departure from the assignment to the NAO index as performed by Pinto et al. (2009), which considered the NAO- index value on the day of maximum cyclone development (and not when they affected Europe). Nevertheless, it turned out that the NAO-index class assigned to a storm day is not sensitive to the introduction of a time lag $(-1,-2,-3$ days, with NAO preceding the storm event).

\section{Analysis of the large-scale circulation and storm days}

3.1. Classification of daily circulation weather types and detection of storm days

The relative frequencies of the different CWTs during the winter half year (October-March) are presented in Figure 2(a). Days with anti-cyclonic flow occur most frequently $(31.6 \%)$, followed by westerly $(22.6 \%)$ and cyclonal (10.0\%) flow. Atmospheric flow from the whole easterly sector (NE, E, SE) is comparatively rare.

Irrespective of the storm detection method applied, a clear dominance of storm days with westerly flow is recognized for the reanalysis period (Figure 2(b)):

Table I. Definition of NAO phases. Index values based on the first PC for North Atlantic/Europe $\left(90^{\circ} \mathrm{W}-50^{\circ} \mathrm{E} ; 20^{\circ} \mathrm{N}-80^{\circ} \mathrm{N}\right)$.

\begin{tabular}{llc}
\hline & \multicolumn{1}{c}{ Phase } & Index values \\
\hline NAO-- & Strong negative & Index $<-1.5$ \\
NAO- & Negative & $-1.5 \leq$ Index $<-0.5$ \\
NAO 0 & Neutral & $0.5 \leq$ Index $<+0.5$ \\
NAO + & Positive & $+0.5 \leq$ Index $<+1.5$ \\
NAO ++ & Strong positive & Index $\geq+1.5$ \\
\hline
\end{tabular}


(a)

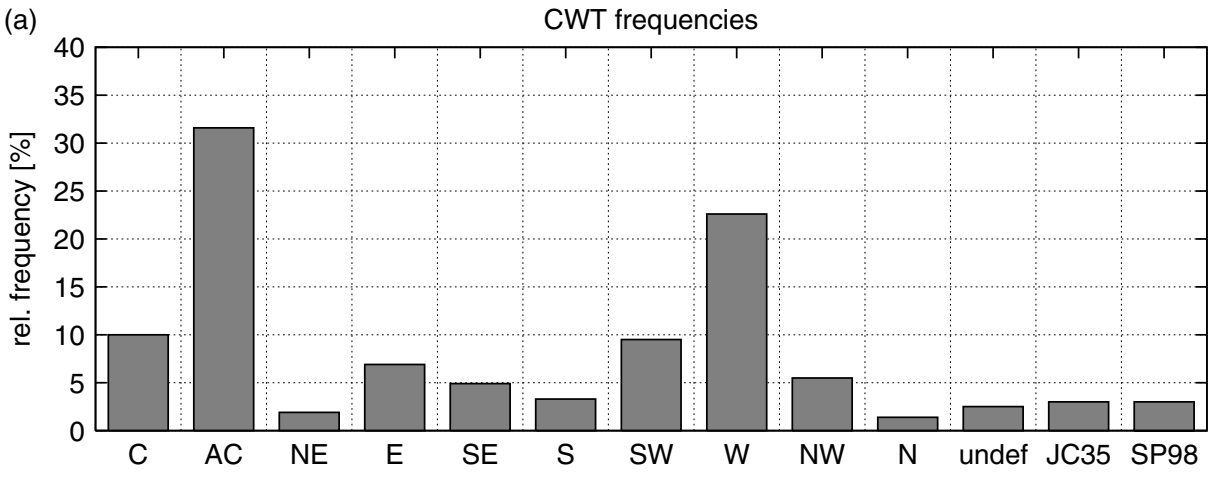

(b)

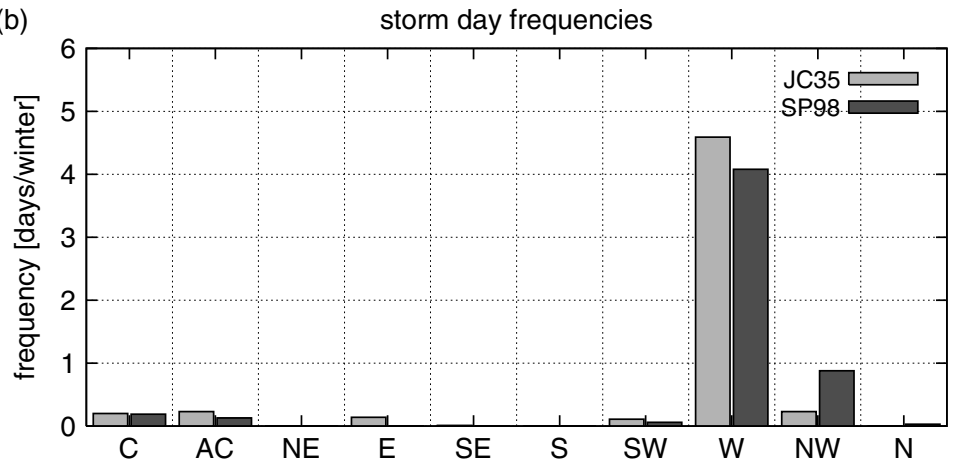

Figure 2. CWT and gale/storm day frequencies during winter half year (ONDJFM). (a) Relative frequencies (unit: \%) for all days. (b) CWTs during gale days JC35 (light grey) and storm days SP98 (dark grey), unit: days per winter.

$80 \%$ (on average, 4.6 days per winter season) of JC35 gale days occur with westerly flow. About 0.2 days per winter season (i.e. approximately 1 day in 5 years) occur during each cyclonal, anti-cyclonal and NW flow; once in 10 years (i.e. 0.1 days per winter) a gale day is analysed with easterly or south-westerly flow, respectively. All other CWT classes are apparently irrelevant for the occurrence of gale days. The SP98 storm days show a similar distribution among the circulation classes. Here also, most of them (about 75\%) occur with westerly flow. The share of flow from north-west in the SP98 storm days is approximately $15 \%$ and thus higher compared to the JC35 counterpart (approximately 4\%).

At first glance, the occurrence of storm days with anti-cyclonal flow character might seem unusual ( $c f$. Figure 2). Detailed examination of these days discloses, however, that they are almost exclusively of hybrid type with westerly or north westerly flow character also. In these cases, at the back side of a cyclone a ridge of high pressure extends over Western Europe (Bay of Biscay or France) and thus causes anti-cyclonal curvature of isobars over Central Europe. The number of 9 gale days (JC35) with anti-cyclonal character results from 16 days with hybrid flow character (which are each counted as half days for AC and thus are responsible for 8 of the 9 counted days); only 1 of the gale days occurs with purely anti-cyclonal flow. From the 16 hybrid anti-cyclonal gale days, we have 15 that feature westerly flow character and 1 with NW flow character. According to the SP98 method, all storm days with AC flow detected from ERA40 are of hybrid character with either westerly or north westerly flow. There is no storm day with purely anti-cyclonal flow.

The similarity of results obtained from the two different methods of storm day identification does not permit a general statement as to which is preferable. The storm events identified by the two different methods coincide to a level of about $70 \%$, i.e. about $30 \%$ of each set are disjoint (typically weaker events). However, in the case of some strong events the detection depends on specific characteristics. For example, fast-moving storms such as Lothar (Dec 26 1999) can hardly be identified from the daily mean MSLP field (JC35, cf. also Ulbrich et al., 2001, their Figure 1(b)), but can clearly be found from daily maximum wind speeds (SP98, $c f$. also Fink et al., 2009). We continue to consider both methods equally within Section 3.

\subsection{CWTs and storm days related to NAO}

The distribution of daily NAO index values in the predefined classes is broadly in accordance with a normal distribution. The majority of all days are associated with neutral NAO (38.9\%) and slightly positive (25.7\%) or slightly negative $(21.5 \%)$ NAO phases, respectively (Figure 3). Days with strong positive (6.4\%) and strong negative $(7.3 \%)$ NAO indices occur with significantly lower frequency. Considering the NAO index values for days in the different CWT classes, we find that each CWT occurred in conjunction with all of the five NAO phases in the ERA40 period (with the exception of northerly flow under $\mathrm{NAO}++$ ). The neutral NAO is the most (or at least the second most) frequent phase for each of the CWTs. 


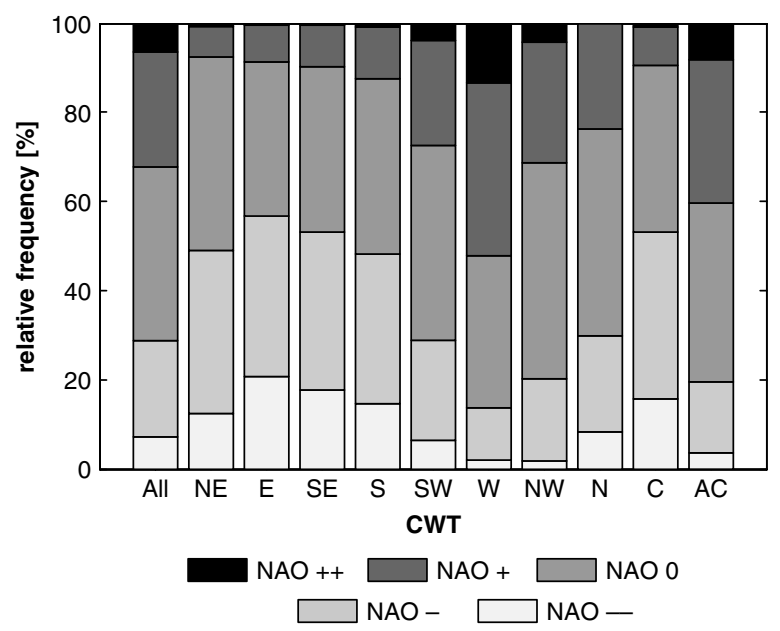

Figure 3. Relative frequency of days during the different NAO phases, for all days and for the different CWT classes (unit: percent of days during winter ONDJFM).

There are, however, some shifts in the distribution, as flow from the easterly sector (NE, E, SE) occurs much more frequently during negative NAO than in positive phases, whereas flow from the westerly sector $(\mathrm{NW}, \mathrm{W}$, $\mathrm{SW}$ ) is mainly assigned to positive NAO. For cyclonal flow, neutral or slightly negative NAO phases are equally frequent. Days with AC flow tend to occur with neutral or slightly positive NAO indices. For the ERA40 period, no statistically significant trends can be found in the number of winter days assigned to a particular NAO index, or to the number of occurrences of the individual CWTs per winter. Still, the seasonal frequencies of some CWTs are significantly (anti-) correlated with the winter (ONDJFM) mean NAO index, namely $\mathrm{W}(r=+0.50)$, $\mathrm{AC}(r=+0.50), \mathrm{C}(r=-0.61)$ and $\mathrm{E}(r=-0.41)$, in agreement with the CWT frequencies during the different NAO classes ( $c f$. Figure 3).

Considering NAO indices for storm days suggests that a slightly positive phase of NAO seems to represent 'optimum conditions' for the occurrence of winter storms in Central Europe with both the JC35 and SP98 approaches (Figure 4). Some spread is found, though the difference to the distribution for all days (full line) remains clear. The detailed relations between NAO and storm days in the different CWT classes are presented in Table II(a) and (b). About $40 \%$ of the gale days are during NAO+; about 30 and $23 \%$ of gale days occur with NAO0 or $\mathrm{NAO}++$, respectively. Only a few storm days occur during a slightly negative NAO phase $(5.1$ and $7.7 \%$ for SP98 and JC35 respectively), and no storms occur during strong negative NAO phases. Strong positive NAO indices $(\mathrm{NAO}++)$ are mainly associated with storms with westerly flow, while the few counts of $\mathrm{NAO}++$ with AC flow are all of hybrid circulation type with $\mathrm{W}$ flow. Storm days with SW or NW flow occur with primarily moderate positive NAO. The few gale days with easterly flow occur with neutral to slightly negative NAO phases; also, the gale days with cyclonal flow characteristics tend to exhibit neutral to slightly negative NAO. About $10 \%$

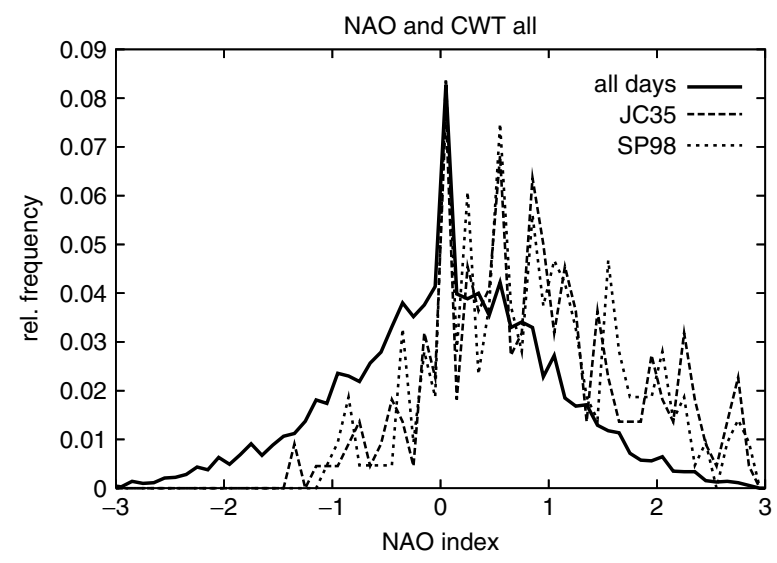

Figure 4. Relative frequencies of NAO indices on storm days JC35 and SP98 in comparison to all days.

of the days during $\mathrm{NAO}++$ are detected as storm days; for $\mathrm{NAO}+$, the percentage of storm days is about $5 \%$.

While the number of storms occurring with a particular combination of NAO phase and CWT is too small to be evaluated in detail, it can be noted that for several CWTs the percentage of storms occurring during a particular non-neutral NAO phase (cf. Table II(a) and (b) generally exceeds the percentage of this combination (Figure 3), enhancing the shifts with respect to the normal distribution of NAO phases. Storm days with W or NW flow occur more frequently during positive NAO phases than would be expected from their frequency during these CWTs. The same is true for the few gale days with easterly flow (defined from JC35) and the slightly negative NAO phases. Again, the distribution of storm days in different NAO phases is similar for both storm identification methods.

\subsection{Characteristics of storm events}

Large-scale atmospheric characteristics related to the storm events are considered in more detail in this section. The mean of the daily maximum wind speeds during JC35 and SP98 gale days in ERA40 is presented in Figure 5(a) and (b) respectively. Maximum wind speeds are found over the ocean areas, in particular the North Sea and Baltic Sea. Over the Central European inland areas, the wind speed values decrease from north to south. The difference between Figure 5(a) and (b) is small. Compared to JC35, SP98 storm days are characterized by somewhat higher wind speeds over Germany. This is due to the definition of SP98 storm days, occurrence of extreme wind speeds in this area being an explicit criterion. As the characteristics for SP98 storm days are very similar to JC35, we concentrate hereafter on presenting detailed analyses of JC35 gale days. The following results are, however, also valid for storm days according to the SP98 criterion.

The track density of cyclones assigned to the storm events is largest over southern Scandinavia (isolines in Figure 5(c)), with tracks mostly extending from the North Atlantic into Northern Europe. On average, the intensity 
Table II. (a) Counts of gale days during the different NAO phases, for all detected days (1st line) and for the different CWT classes for JC 35 gale days, (b) Same as (a), but for SP98 storm days.

\begin{tabular}{lcccccc}
\hline & Total number & NAO- $(\%)$ & NAO- $(\%)$ & NAO 0 (\%) & NAO+ $(\%)$ & NAO++ $(\%)$ \\
\hline Gale days JC35 (all) & 220.0 & 0 & 7.7 & 29.1 & 40.5 & 22.7 \\
JC35 with NE & 0 & 0 & 0 & 0 & 0 & 0 \\
JC35 with E & 5.5 & 0 & 63.6 & 36.4 & 0 & 0 \\
JC35 with SE & 0.5 & 0 & 100 & 0 & 0 & 0 \\
JC35 with S & 0 & 0 & 0 & 0 & 0 & 0 \\
JC35 with SW & 4.5 & 0 & 0 & 88.9 & 11.1 & 0 \\
JC35 with W & 183.5 & 0 & 4.4 & 28.6 & 42.8 & 24.2 \\
JC35 with NW & 9.0 & 0 & 0 & 11.1 & 0 & 0 \\
JC35 with N & 0 & 0 & 50.0 & 37.5 & 12.5 & 0 \\
JC35 with C & 8.0 & 0 & 0 & 16.7 & 22.2 & 0 \\
JC35 with AC & 9.0 & & 0 & & & 61.1
\end{tabular}

2nd column: total number of days in CWT class, columns 3 to 7 : percent of days in each NAO phase.

\begin{tabular}{lcccccc}
\hline & Total Number $(\%)$ & NAO-- $(\%)$ & NAO- $(\%)$ & NAO 0 (\%) & NAO+ $(\%)$ & NAO++ $(\%)$ \\
\hline Storm days SP98 (all) & 214.0 & 0 & 5.1 & 32.3 & 38.8 & 23.8 \\
SP98 with NE & & 0 & 0 & 0 & 0 & 0 \\
SP98 with E & & 0 & 0 & 0 & 0 & 0 \\
SP98 with SE & & 0 & 0 & 0 & 0 & 0 \\
SP98 with S & 2.5 & 0 & 0 & 0 & 0 & 0 \\
SP98 with SW & 163.0 & 0 & 0 & 60.0 & 0 & 40.0 \\
SP98 with W & 35.0 & 0 & 3.4 & 31.3 & 38.3 & 27.0 \\
SP98 with NW & 1.0 & 0 & 100 & 3.7 & 50.0 & 11.4 \\
SP98 with N & 7.5 & 0 & 33.3 & 46.7 & 0 & 0 \\
SP98 with C & 5.0 & 0 & 0 & 30.0 & 30.0 & 0 \\
SP98 with AC & & & & & & 40.0 \\
\end{tabular}

(Laplacian P) of the storm-producing cyclones is highest over eastern North Atlantic, between Iceland and British Isles (coloured areas in Figure 5(c)).

To gain a deeper insight into the relationship between the occurrence of storm situations and the large-scale flow, atmospheric patterns associated with identified gale days in different CWTs will now be considered. Consideration of gale indices and wind speeds revealed that the few gale days with flow from the easterly sector are less relevant not only in terms of their frequency but also in terms of intensity (not shown). Thus, we concentrate on gale days occurring in the CWT classes SW, W, NW, C and AC. Anomalies of MSLP patterns from the winter mean state ( $c f$. Figure 6), wind speeds and associated cyclone tracks for JC35 gale days in these classes are presented in Figure 7. Note that results with respect to CWTs other than $\mathrm{W}$ are computed from a comparatively low number of events. Nevertheless, the pressure anomalies for the composites of storm days are significantly stronger compared to the composites of all days in each CWT class ( $c f$. Figure 7 , left side).

- Storm days with W flow (Figure 7(a)): The position of mean low pressure is over the northern North Sea, whereas high pressure prevails over south-west Europe. This reflects the definition of this CWT over Central Europe, but also shows the extension of low pressure anomalies to Scandinavia. The plots of associated cyclone tracks correspond well to those presented in Figure 5 for all gale days, as the total volume is dominated by those with $\mathrm{W}$ flow. The same reasoning leads to the absence of major deviation from the wind distribution averaged over all events (Figure 7(a), right column). A high correlation ( $r=$ 0.75) was found between the seasonal frequency of $\mathrm{W}$ storm days and the seasonal frequency of all $\mathrm{W}$ days (i.e. irrespective of whether it is a storm day or not). Further, the frequency of storm days with W flow also reveals a significant correlation with the seasonal NAO index. Most of the severe historical storms occurred in this class, such as 'Daria' (January 25/26, 1990), 'Wiebke' (February 28, 1990) or 'Anatol' (December 3, 1999; cf. Ulbrich et al., 2001).

- Storm days with NW flow in the Central European investigation area (Figure 7(b)) seem to be of enhanced relevance for eastern Central Europe, as highest wind speeds occur over inland areas of Poland and the eastern part of Germany during storms in this CWT class. High mean values of maximum daily wind speeds are found compared to storms in other classes over the North Sea also. The mean pressure minimum is located over the Baltic Sea; the mean position of highest pressure is over the Bay of Biscay. Cyclones move on a ridgelike path from North Atlantic to North 
(a)

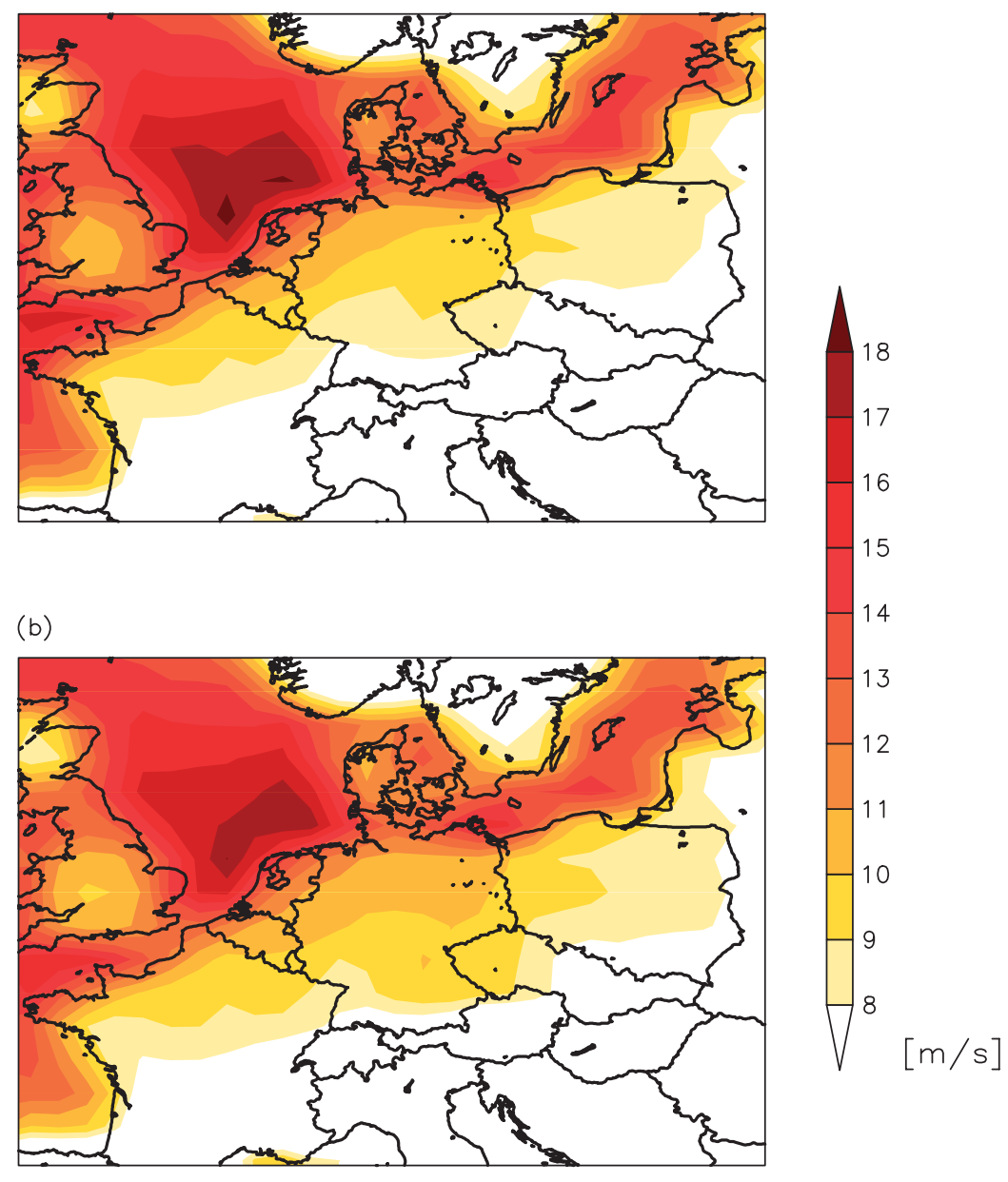

(c)

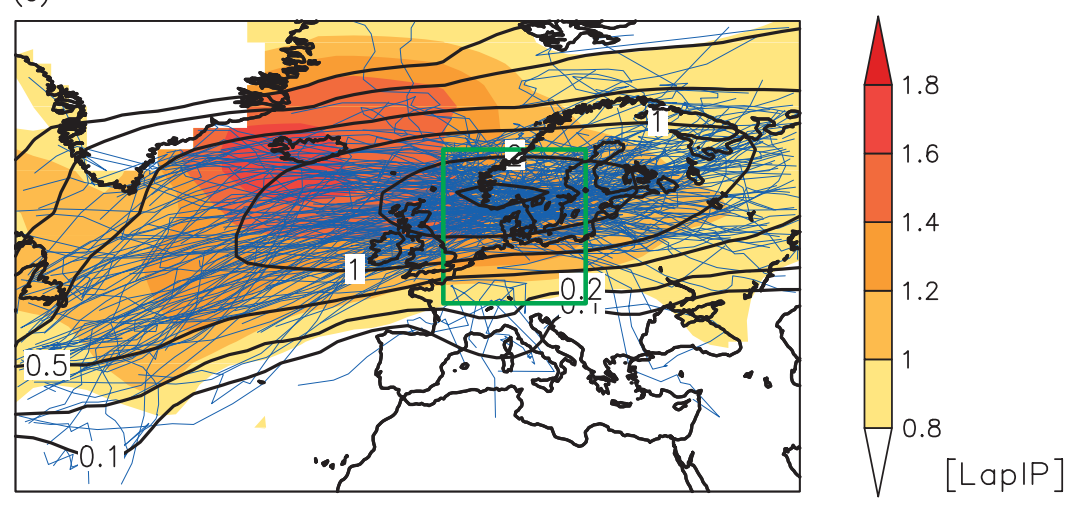

Figure 5. Wind speeds and cyclones in relation to storm events. (a) Mean of daily maximum wind speeds during JC 35 gale days in ERA40 reanalysis (unit: $\mathrm{m} / \mathrm{s}$ ), (b) same as (a) but for SP98 storm days, (c) cyclone tracks assigned to JC35 gale days in ERA40. Contour lines show track densities (unit: tracks/winter), Shaded areas show intensity (Laplacian $\mathrm{P}$, unit: $\mathrm{hPa} /(\mathrm{deg} . l \mathrm{lat})^{2}$ ) of the cyclones. Green box: cyclone detection box, i.e. search area for strongest cyclone in relation to gale days.

Sea and then further east over Scandinavia to the Baltic Sea. The mean intensity of cyclones is relatively high far into eastern parts of the tracks; e.g. Laplacian $\mathrm{P}$ values higher than $1.2 \mathrm{hPa} /\left(\mathrm{deg} . l^{\text {at }}\right)^{2}$ are found over the Baltic Sea, which help in explaining the high wind speeds in eastern areas (cf. Figure 7(b), right column). The storm 'Ornella' (January 10, 1995) is the representative for this class. It travelled quickly on a pathway from North Atlantic, south of Iceland towards South Sweden and to the Baltic Sea and reached a minimum pressure of $965 \mathrm{hPa}$. At the same time, a strong anti-cyclone $(1045 \mathrm{hPa})$ was located over the eastern Atlantic. The steep pressure gradient between both systems caused a strong NW-flow. In List (Island of Sylt), wind speeds of up to $39 \mathrm{~m} / \mathrm{s}$ were measured (Berliner Wetterkarte, 2009). Severe 


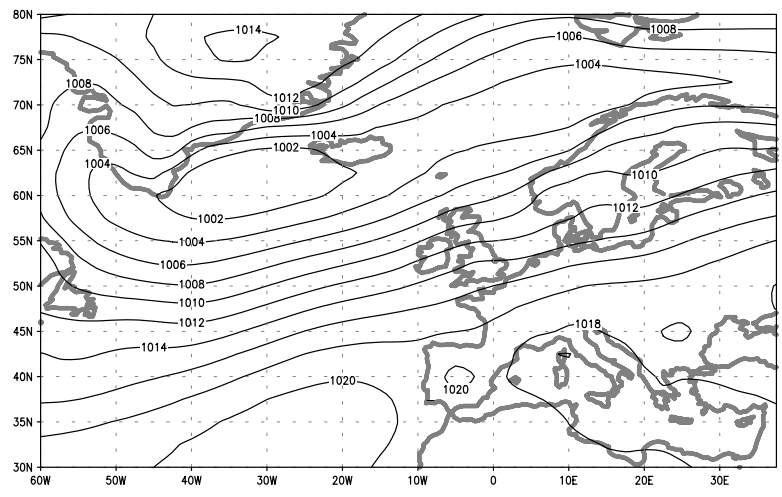

Figure 6. Mean MSLP field for winter months ONDJFM in ERA40, 1961-2000 (unit: hPa).

gusts also occurred over inland areas (particularly in eastern parts of Germany, e.g. Schwerin $28 \mathrm{~m} / \mathrm{s}$, Potsdam $25 \mathrm{~m} / \mathrm{s}$ and Goerlitz $25 \mathrm{~m} / \mathrm{s}$ ).

- Storm days with SW flow (Figure 7(c)): The minimum of averaged MSLP is located over eastern Atlantic, close to the British Isles, whereas there is high pressure over southern Europe. Cyclones associated with storms with SW flow at the surface when they reach Central Europe typically reach their maximum intensity over or close to the United Kingdom. Wind speeds are highest over western Europe; the eastern part of Central Europe is less or not affected by those events. An example of a storm in this class is the extratropical cyclone 'Oralia' (October 30, 2000). This was a rapidly developing secondary disturbance, moving fast around a relatively deep $(960 \mathrm{hPa})$ stationary depression over Scotland. Oralia reached a minimum pressure of $940 \mathrm{hPa}$ over the North Sea and caused gale-force winds over the German Bight. Here, the light vessel 'TW EMS' registered a gust of $39 \mathrm{~m} / \mathrm{s}$ (Berliner Wetterkarte, 2009). Strong gusts were also measured over western and Central European inland areas (e.g. Vlissingen $27 \mathrm{~m} / \mathrm{s}$, Trier $28 \mathrm{~m} / \mathrm{s}$, Aachen $27 \mathrm{~m} / \mathrm{s}$ ).

- Storm days with C flow (Figure 7(d)): The localized pressure anomaly over Central Europe can be related to the definition of this CWT. The tracks of the associated cyclones are approaching Europe partly from the west and partly from the Mediterranean area. Cyclones are relatively weak over Central Europe (with maximum intensities over the central North Atlantic), and so are maximum wind speeds. In Central Europe, the impact of storms in this class is thus weaker than average (Figure 7(d)). A storm situation identified in this class occurred e.g. on February 01, 1986. With a cyclone over the western Mediterranean, a shortwave trough moved northwards to the Alps. There were strong southerly foehn winds with gale-force gusts (Zugspitze $37.5 \mathrm{~m} / \mathrm{s}$, Augsburg $20 \mathrm{~m} / \mathrm{s}$ ) north of the Alps, while strong easterly winds occurred (Helgoland $28 \mathrm{~m} / \mathrm{s}$, Schwerin $20 \mathrm{~m} / \mathrm{s}$, Hannover $19 \mathrm{~m} / \mathrm{s}$ (Berliner Wetterkarte, 2009)) over central and northern German areas.
- Storm days with AC flow (Figure 7(e)) are connected to cyclones on a more northerly track. The mean depression is located over Scandinavia and the Baltic Sea and high pressure over southern Europe. Such a situation typically occurs on the back side of a cyclone, when relatively high pressure can extend northwards as far as Central Europe, leading to an anti-cyclonic bend of isobars (almost all of the storm days in this class are of hybrid type with W/NW flow, $c f$. section 3.1). Associated cyclones propagate far eastwards, and their intensity is still relatively high (Lapl. $P>1.0 \mathrm{hPa} /(\text { deg.lat })^{2}$ ) over Baltic States and northern Russia. Thus, storm days of this class are also connected with high wind speeds, particularly over eastern Central Europe and eastern Europe. Note that the storm days classified as (hybrid) AC over Germany are likely to have directional (W or NW) characteristics over this region. Besides the single storm situation with purely anti-cyclonic flow characteristics (December 09, 1980), the storm 'Verena' (January 13, 1993) is another example identified in this class. This storm day, however, has hybrid AC and W flow characteristics. It is related to a rapidly developing cyclone that travelled quickly from the North Atlantic, over southern England (where it deepened more than $10 \mathrm{hPa}$ in $3 \mathrm{~h}$ ), along the coasts of the North and Baltic Seas towards the Baltic States. On its back side emerged a high pressure ridge over western Europe, causing the hybrid anti-cyclonic flow. Gale-force wind speeds were measured at the coast as well as over inland areas (Helgoland $39 \mathrm{~m} / \mathrm{s}$, Schwerin $38 \mathrm{~m} / \mathrm{s}$, Duesseldorf $34 \mathrm{~m} / \mathrm{s}$ (Berliner Wetterkarte, 2009)).

Thus, using a gale day definition focused on Central Europe, the different CWTs associated with the storms yield different specific characteristics of the synoptic situation. An extension of high wind speeds into eastern Central Europe, for example, can be found in connection with NW flow or hybrid AC flow, as the cyclones still retain a relatively high intensity over the Baltic Sea. By contrast, during SW flow situations, cyclones often lose intensity earlier (e.g. due to landfall) and do not move so far east, explaining a focus of highest wind speeds over the western parts of Central Europe. The vast majority of storms, however, occur with westerly flow over Central Europe.

\section{Summary, discussion and conclusions}

In this paper, we identified storms over Central Europe by two different methods: One is based on the relatively simple CWT approach, with storm events defined from a gale parameter originally developed by Jenkinson and Collison, 1977 and Jones et al., 1993. The other is defined from local winds at ERA40 grid points in Germany exceeding the $98 \%$ percentile threshold, which is relevant for storm damage. Only $70 \%$ of the storm events identified by the two methods were identical, but no large differences were found with respect to the 
(a) W
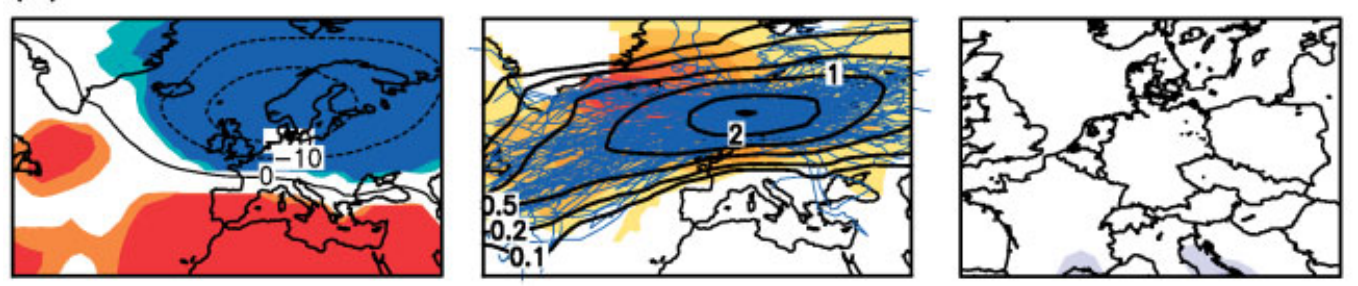

(b) NW
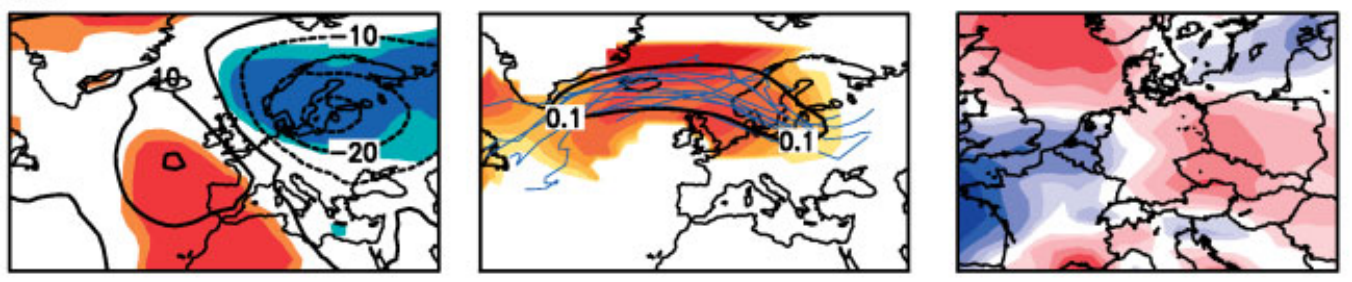

(c) SW
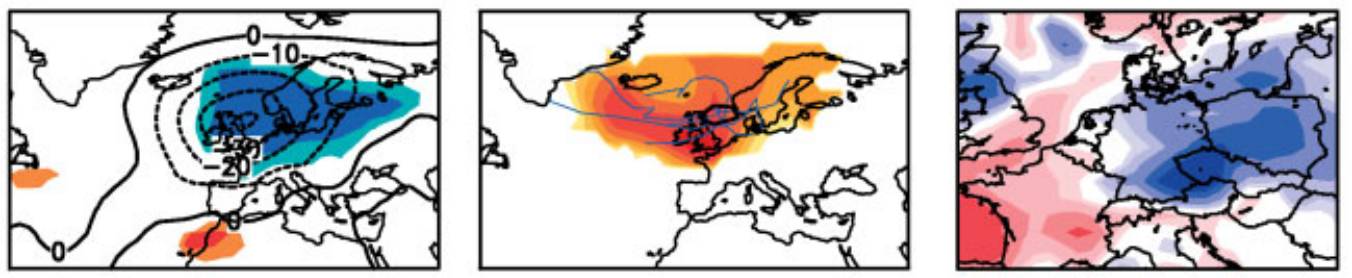

(d) $\mathrm{C}$
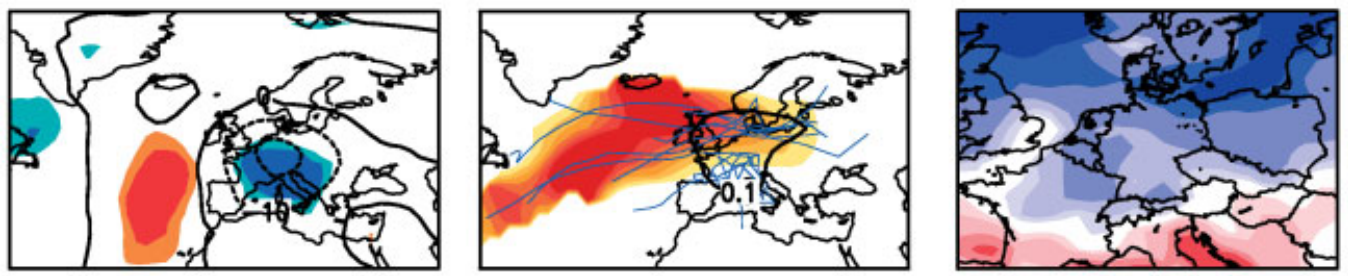

(e) AC
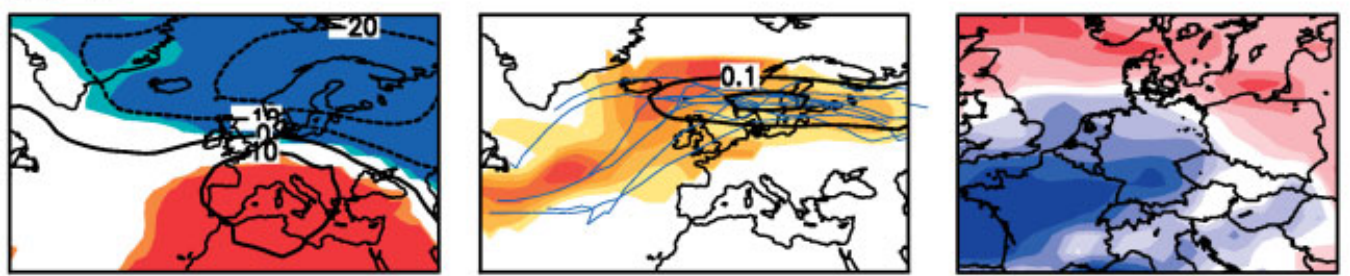

[Lopl. P]

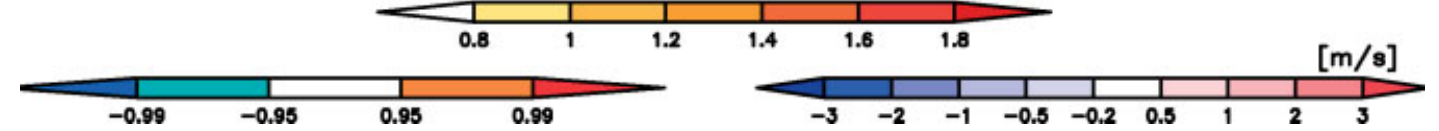

Figure 7. Atmospheric features in relation to JC35 gale days in ERA40, separated for relevant CWTs. Left column: Anomaly of mean MSLP field for storm days in each CWT class from the respective mean MSLP field for winter in Figure 6 (unit: hPa). Shaded areas indicate zones where the pressure anomalies are significantly higher (red) or lower (blue) compared to all days in each CWT class (Student $t$-test); middle: related cyclones (blue lines $=$ tracks, black contour lines $=$ track density, unit: tracks/winter; shaded areas $=$ mean intensity of cyclones, Laplacian $P$, unit: $\left.\mathrm{hPa} /(\operatorname{deg} . l a t)^{2}\right)$; right column: anomaly of mean of daily maximum wind speed on storm days in each CWT class from mean of daily maximum wind speed on all storm days in Figure 5(a) (unit: m/s).

assignment of storms and a daily NAO index, and with respect to the association of storms and the CWTs on storm days. The days differing between the two methods primarily concern weaker events. Despite the partial disjunction of both sets of storm days, the associated atmospheric features such as large-scale atmospheric flow in terms of NAO and CWTs, cyclone tracks and assigned wind speeds turn out to be very similar. Thus, we conclude that the gale index is a simple but suitable parameter to identify damaging storm events in this region. This permits future investigations on storms in multi-model ensembles based on this simple measure. 
Most of the Central European storm days are associated with westerly flow regimes (about $80 \%$ ) and with a positive NAO phase, the latter being computed on a daily basis. Only between 5 and $7 \%$ of storm days (depending on the specific storm definition) have occurred in conjunction with modestly negative NAO phases, and none with a strongly negative NAO index value. Neutral NAO phases are somewhat underrepresented in the occurrence of storms, as most of the events occur during a modestly positive phase. Strong positive NAO phases (only $6.4 \%$ of all days) have a share of more than $20 \%$ of the storms. Thus, about $10 \%$ of all days with a strongly positive NAO index and about $5 \%$ of those with a modestly positive index are associated with a storm over central Europe. It should be kept in mind that, on the other hand, the cyclones themselves play a major role in steering the NAO phase (e.g. Benedict et al., 2004). Thus, the existence of cyclone systems over the North Atlantic itself has an influence on the NAO index (e.g. Schneidereit et al., 2007). Our results complement previous studies on the relation between storms and NAO (e.g. Pinto et al., 2009), which investigated the occurrence of deep cyclones for different NAO phases, but did not account for the affected regions. The results seem to be in line with studies on storms and on the NAO in climate change experiments, suggesting an increasing NAO index and an increasing storminess with increasing GHG forcing (e.g. Pinto et al., 2007b).

Distinguishing the different CWTs for the days of storm occurrence, the results for the most relevant westerly flow are very similar to the overall results. They are characterized by cyclones travelling from the North Atlantic to the British Isles, the North Sea and southern Scandinavia. On average, the intensity of the cyclones related to storms has its maximum over the eastern North Atlantic, between Iceland and the British Isles.

Whereas storm days with $\mathrm{W}$ flow are of highest relevance in terms of their frequency, storm days with NW flow seem to be of highest relevance in terms of their intensity. In the observed set of storms, highest wind speeds over (Central European) inland areas and also over the North Sea occur for storm days in this class. The associated cyclones follow a ridge-like path north of the British Isles into the North Sea, and their intensity remains relatively high far eastwards into the Baltic Sea. Nevertheless, most of the severe and historically very loss-intensive storms are associated with $\mathrm{W}$ flow. The comparatively lower average wind speed for storm days with westerly flow is apparently due to a large number of weaker events in this class. This is distinct for NW flow, for which only a comparatively smaller number of weaker events are found. This result could be a sampling phenomenon, but a physical background associated with storm cyclone tracks predominantly travelling over sea cannot be excluded. Cyclones associated with NW storms travel over sea before and are thus still comparatively intense when affecting Central Europe. By contrast, cyclones on more southern tracks (associated with other flow classes such as W) typically make landfall earlier and lose intensity accordingly.

The relatively simple CWT approach in conjunction with the two storminess identification methods presented here provides realistic and reasonable results for the investigation of storm situations. The results obtained for the relation of wind storms and tropospheric conditions agree with findings from other studies on, for example, the occurrence of storms primarily during positive NAO phases (Raible, 2007; Pinto et al., 2009) or the importance of westerly flow for storms affecting Central Europe (Schmidtke and Scherrer, 1997; Busch et al., 1998). Additionally, the presented CWT approach allows for quantification of storm events as well as of the different flow classes and its related atmospheric features.

Flow directions typically change during the passage of a cyclone from SW flow on its front side when the cyclone approaches, rotating further to $\mathrm{W}$ to $\mathrm{NW}$ on the back side of the cyclone. Thus, it is expected that for consecutive storm days the same cyclone track may contribute to the composites of different flow classes (e.g. $\mathrm{SW}, \mathrm{W}$ and NW). Consecutive storm days (as identified here) related to different CWTs occur, but only rarely. During the 40-year reanalysis period, e.g. for JC35, there are 55 cases of consecutive storm days, only 7 of which feature changes of flow direction (generally from $\mathrm{W}$ to NW). Leckebusch et al. (2008b) investigated weather situations leading to storm in Central Europe by means of a cluster analysis that also considers the temporal evolution over 3 days. Surveying the pressure patterns associated with the primary storm clusters (their Figure 3 ) confirms that the geostrophic flow direction over Central Europe undergoes only small changes during the 3-day episodes and further illustrates the dominance of westerly flow.

A further quality of the present study is its detailed investigation of atmospheric conditions and cyclone systems related to storm events. Such a detailed examination on the relation between storms affecting Central Europe and associated atmospheric features may help in enhancing the understanding of European storm events. The detailed factors influencing the development and pathway of cyclones close to Europe need to be investigated in further studies. This is desirable in order to understand particular characteristics of cyclones related to storm days of different CWTs, e.g. the ridge-like characteristic of cyclone tracks and their relatively high intensity associated with NW storms.

\section{Acknowledgements}

This work was supported by the ENSEMBLES project, funded by the European Commission's 6th Framework Programme through contract GOCE-CT-2003-505539. We particularly thank Stefan Zacharias (Univ. Cologne) for computing the daily NAO index for the ERA40 dataset. We kindly thank ECMWF, DWD (German Weather Service) and DKRZ (German Climate Computing Centre) for ERA-40 data use and availability. We are also grateful to two anonymous reviewers for their 
detailed comments, which helped to focus the manuscript and improve its clarity.

\section{References}

Bärring L, von Storch H. 2004. Scandinavian storminess since about 1800. Geophysical Research Letters 31: L20202, DOI: 10.1029/2004GL020441.

Benedict JJ, Lee S, Feldstein SB. 2004. A synoptic view of the North Atlantic Oscillation. Journal of the Atmospheric Sciences 61: $121-144$.

Berliner Wetterkarte. 2009. published by Verein BERLINER WETTERKARTE e.V., ISSN 0177-3984, http://www.berlinerwetterkarte.de.

Blessing S, Fraedrich K, Junge M, Kunz T, Lunkheit F. 2005. Daily North-Atlantic Oscillation (NAO) index: statistics and its stratospheric polar vortex dependence. Meteorologische Zeitschrift 14: 763-769.

Buishand A, Brandsma T. 1997. Comparison of circulation classification schemes for predicting temperature and precipitation in the Netherlands. International Journal of Climatology 17: 875-889.

Busch U, Beckmann BR, Roth R. 1998. Study of storm weather situations in observation and ECHAM3/T42 model simulation. Tellus 50A: $411-423$.

Carnell RE, Senior CA, Mitchell JFB. 1996. An assessment of measures of storminess: simulated changes in northern hemisphere winter due to increasing CO2. Climate Dynamics 12: 467-476.

Della-Marta PM, Mathis H, Frei C, Liniger MA, Kleinn J, Appenzeller C. 2009. The return period of wind storms over Europe. International Journal of Climatology 29: 437-459, DOI: 10.1002/joc. 1794

Demuzere M, Werner M, van Lipzig NPM, Roeckner E. 2008. An analysis of present and future ECHAM5 pressure fields using a classification of circulation patterns. International Journal of Climatology (in press), DOI: 10.1002/joc.1821.

Fink AH, Brücher T, Ermert E, Krüger A, Pinto JG. 2009. The European Storm Kyrill in January 2007: synoptic evolution, meteorological impacts and some considerations with respect to climate change. Natural Hazards and Earth System Sciences 9: $405-423$.

Goodess CM, Palutikof JP. 1998. Development of daily rainfall scenarios for southeast spain using a circulation-type approach to downscaling. International Journal of Climatology 10: 1051-1083.

Hess P, Brezowsky H. 1969. Katalog der Großwetterlagen Europas, 3. Aufl, Berichte des Deutschen Wetterdienstes Nr. 113, Vol. 15, 2nd edn. Deutscher Wetterdienst: Offenbach am Main; 70 (In German).

Hulme M, Jones PD. 1991. Temperatures and windiness over the United Kingdom during the winters of 1988/89 and 1989/1990 compared with previous years. Weather 46: 126-136.

Hurrell JW. 1995. Decadal trends in the North Atlantic Oscillation: regional temperatures and precipitation. Science 269: 676-679.

Jenkinson AF, Collison FP. 1977. An initial climatology of gales over the North Sea. Synoptic Climatology Branch Memorandum No. 62. Meteorological Office: Bracknell (unpublished). Available from the National Meteorological Library, Meteorological Office: Bracknell.

Jones PD, Hulme M, Briffa KR. 1993. A comparison of Lamb circulation types with an objective classification scheme. International Journal of Climatology 13: 655-663.

Klawa M, Ulbrich U. 2003. A model for the estimation of storm losses and the identification of severe winter storms in Germany. Natural Hazards and Earth System Sciences 3: 725-732.

Lamb HH. 1972. British Isles Weather Types and a Register of the Daily Sequence of Circulation Patterns, 1861-1971, Geophysics Memoirs 116. HMSO: London; 85.

Leckebusch GC, Ulbrich U, Fröhlich L, Pinto JG. 2007. Property loss potentials for European midlatitude storms in a changing climate. Geophysical Research Letters 34: L05703, DOI: 10.1029/2006GL027663.

Leckebusch GC, Renggli D, Ulbrich U. 2008a. Development and application of an objective storm severity measure for the Northeast Atlantic region. Meteorologische Zeitschrift 17: 575-587.

Leckebusch GC, Weimer A, Pinto JG, Reyers M, Speth P. 2008 b. Extreme wind storms over Europe in present and future climate: a cluster analysis approach. Meteorologische Zeitschrift 17: 67-82.

Marshall J, Kushnir Y, Battisti D, Chang P, Czaja A, Dickson R, Hurrell J, McCartney M, Saravanan R, Visbeck M. 2001. North
Atlantic climate variability: phenomena, impacts and mechanisms. International Journal of Climatology 21: 1863-1898.

Matulla C, Schöner W, Alexandersson H, von Storch H, Wang XL. 2008. European storminess: late nineteenth century to present. Climate Dynamics 31: 125-130.

Munich Re. 1999. Naturkatastrophen in Deutschland: Schadenerfahrungen und Schadenpotentiale, Publication of the Munich Re, Order Number 2798-E-d www.munichre.com.

Munich Re. 2007. Zwischen Hoch und Tief-Wetterrisiken in Mitteleuropa, Eidition Wissen, Publication of the Munich Re, Order Number 302-05481, www munichre.com.

Murray RJ, Simmonds I. 1991. A numerical scheme for tracking cyclone centres from digital data. Part I: Development and operation of the scheme. Australian Meteorological Magazine 39: 155-166.

Pinto JG, Spangehl T, Ulbrich U, Speth P. 2005. Sensitivities of a cyclone detection and tracking algorithm: individual tracks and climatology. Meteorologische Zeitschrift 14: 823-838.

Pinto JG, Fröhlich EL, Leckebusch GC, Ulbrich U. 2007a. Changing European storm loss potentials under modified climate conditions according to ensemble simulations of the ECHAM5/MPI-OM1 GCM. Natural Hazards and Earth System Sciences 7: 165-175.

Pinto JG, Ulbrich U, Leckebusch GC, Spangehl T, Reyers M, Zacharias S. 2007b. Changes in storm track and cyclone activity in three SRES ensemble experiments with the ECHAM5/MPI-OM1 GCM. Climate Dynamics 29: 195-210, DOI: 10.1007/s00382-0070230-4.

Pinto JG, Zacharias S, Fink AH, Leckebusch GC, Ulbrich U. 2009. Factors contributing to the development of extreme North Atlantic cyclones and their relationship with the NAO. Climate Dynamics 32: 711-737, DOI: 10.1007/s00382-008-0396-4.

Raible CC. 2007. On the relation between extremes of mitlatitude cyclones and the atmospheric circulation using ERA40. Geophysical Research Letters 34: L07703, DOI: 10.1029/2006GL029084.

Schmidtke H, Scherrer HU. 1997. Sturmschäden im Wald. Swiss National Science Foundation, NFP 31. vdf - Hochschulverlag AG: ETH Zürich, 38.

Schneidereit A, Blender R, Fraedrich K, Lunkheit F. 2007. Iceland climate and North Atlantic cyclones in ERA40 reanalyses. Meteorologische Zeitschrift 16: 17-23.

Serreze MC, Carse F, Barry RG, Rogers JC. 1997. Icelandic Low cyclone activity: climatological features, linkages with the NAO and relationships with recent changes elsewhere in the Northern Hemisphere circulation. Journal of Climate 10: 453-464.

Trigo RM, Dacamara CC. 2000. Circulation weather types and their influence on the precipitation regime in Portugal. International Journal of Climatology 20: 1559-1581.

Ulbrich U, Fink A, Klawa M, Pinto JG. 2001. Three extreme storms over Europe in December 1999. Weather 56: 70-80.

Uppala SM, Allberg K, Simmons PW, Andrae AJ, Da Costa U, Bechtold V, Fiorino M, Gibson JK, Haseler J, Hernandez A, Kelly GA, Li X, Onogi K, Saarinen S, Sokka N, Allan RP, Andersson E, Arpe K, Balmaseda MA, Beljaars ACM, Van De Berg L, Bidlot J, Bormann N, Caires S, Chevallier F, Dethof A, Dragosavac M, Fisher M, Fuentes M, Hagemann S, H'olm E, Hoskins BJ, Isaksen L, Janssen PAEM, Jenne R, Mcnally AP, Mahfouf JF, Morcrette JJ, Rayner NA, Saunders RW, Simon P, Sterl A, Trenberth KE, Untch A, Vasiljevic D, Viterbo P, Woollen J. 2005. The ERA-40 re-analysis. Quarterly Journal of the Royal Meteorological Society 131: 2961-3012.

van Bebber WJ. 1891. Die Zugstrassen der barometrischen Minima. Meteorologische Zeitschrift 8: 361-366.

Walker GT. 1924. Correlations in seasonal variations of weather IX Memoirs of India Meteorological Department 24: 275-332.

Wang XL, Zwiers FW, Swail VR, Feng Y. 2009. Trends and variability of storminess in the Northeast Atlantic Region, 1874-2007. Climate Dynamics (in press), DOI: 10.1007/s00382008-0504-5.

Wanner H, Bronnimann S, Casty C, Gyalistras D, Luterbacher J, Schmutz C, Stephenson DB, Xoplaki E. 2001. North Atlantic Oscillation - concepts and studies. Surveys in Geophysics 22: 321-382.

WASA. 1998. Changing waves and storms in the Northeast Atlantic? Bulletin of the American Meteorological Society 79: 741-760.

Wernli H, Dirren S, Liniger MA, Zillig M. 2002. Dynamical aspects of the life cycle of the winter storm 'Lothar' (24-26 December 1999). Quarterly Journal of the Royal Meteorological Society 128: 405-429. 